International Journal of Instruction e-ISSN: 1308-1470 • www.e-iji.net
July $2019 \bullet$ Vol.12, No.3

p-ISSN: 1694-609X

pp. 561-576

Received: 03/12/2018

Revision: 16/04/2019

Accepted: $21 / 04 / 2019$

OnlineFirst: 12/05/2019

\title{
The Impact of Organizational Stressors on Job Performance among Academic Staff
}

\section{Midya Yousefi}

Dr., School of Educational Studies, University Sains Malaysia, Malaysia, midya.yousefi@gmail.com

\section{Abdul Ghani Kanesan Abdullah}

Prof., School of Educational Studies, University Sains Malaysia,agk@usm.my

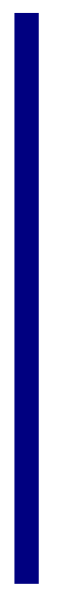

This study investigate to test and analyse the influence of organizational stressors include role ambiguity, role conflict, and workload on job performance among academic staff. The data were collected by structured questionnaires through cluster sampling techniques and 209 academic staff from research universities inside Malaysia completed the questionnaires. Partial least squares structural equation modeling (PLS-SEM), has been employed to perform the analysis. The outcomes of Smart PLS have been assessed through measurement model and structural model. The result identify that role ambiguity is the major predictors of organizational stressors that influenced adversely on academics performance. Also, role conflict is the second predictors that negatively effects on the job performance of academics staff but not workload. This research makes significant theoretical and practical implications to enrich the existing literature on organizational stressors and contribute to academic staff job performance, and help existing policy makers and administrators of universities to reduce adverse impacts of organizational stress factors and manage to enhance academics performance.

Keywords: organizational stressors, role ambiguity, role conflict, workload, job performance, research university, partial least squares

\section{INTRODUCTION}

Stress has been a growing problem in organizations and there is a major issue in the universities nowadays. Also, organizational stress caused unfavourable effects on academic's job performance. Meanwhile, in higher education sectors some researchers mentioned that university staff play a vital role in the creation and development of knowledge and innovation in addition to education and training (Gillespie et al., 2001). Though, academic staff recently received job stress due to passing through an age of transition of constant global changes, especially major changing in curriculum design

Citation: Yousefi, M., \& Abdullah, A. G. K. (2019). The Impact of Organizational Stressors on Job Performance among Academic Staff. International Journal of Instruction, 12(3), 561-576. https://doi.org/10.29333/iji.2019.12334a 
and dynamic multi task duties, resulting in creation of high performance expectation to be met in universities (Kaur et al., 2018). Besides, according to Jacob et al. (2015) being successful academic staff who work in universities depending on having a clear understanding of how to combine the elements of teaching, research and original creative work, and service in a way that makes the best use of the time. Consequently, academic staff are subjected to intense role ambiguity and role conflict which hamper their working performance and consumed as stressors of the organizational stress. Further, the number of university students are increasing, thus adding workload to academic staff related to teaching and student supervision (Kinman, 2008). In a bid to achieve universities goals, the academic staff need to work harder to bring adequate output such as production of papers for publication in high impact journals, application of research grants, student supervision and teaching activities, in addition, conducting of qualitative and quantitative researches (Murphy, 2014). In developed countries such as the UK, New Zealand, US and Australia, the global changing in curriculum design and technology has led to a notable demands in public universities. While, academics organizational stress studies conducted in China and Japan illustrated that academic staff subjected to organizational stressors in public universities regarding to job performance in these universities in relation to effectiveness of course delivery, quality of course content, effectiveness in developing and managing instruction, effectiveness in mentoring students, effectiveness of academic advising, and using research and original creative work and service to enhance teaching (Jonker, 2016; Lin Li, 2012).

Likewise, Ahsan et al. (2009) stated that the number of universities in Malaysia has increased tremendously for the past few years. Due to the increasing number of universities in Malaysia, academic staff may face more problems in their job because the management is facing competitive pressure from other universities. Many universities are now setting new goals to compete with other universities, and therefore the academic staff are involving with the ultimate goal. This may cause university academic staff to face plenty of stress regarding to their job expectations. The difference between types of universities could be a factor that makes the difference in levels of workload, role ambiguity and role conflict that directly resulting in job performance complexity among university academic staff. Based on the above phenomenon, it should be highlighted that there is a major problem in research to recognize and eliminate organizational stressors that negatively influence on academic staff performance who work in research universities in Malaysia. More important, all of the above pressures could lead to job stress and impede their productivity as well as health and commitment. Similarly, Ram (2013) noted that the aim of introducing the status of research universities inside Malaysia is to develop research, innovation and teaching level to excellence class in higher education. Hence, the aim of this study is to bring more understanding to the concept of role ambiguity, role conflict and workload that are the challenging predictors as if associated negatively on academic staff performance in research universities. Thus, as highlighted above, towards the significance of job performance and organizational stress among academics, this research hopes to serve as guidance and a stepping stone for further studies in various aspects of improving the quality and productivity among the academic staff of research universities. This aspect can be achieved by 
understanding the difference between organizational stressors that spread in research universities. According to Baron and Greenberg (2003), role ambiguity remains more popular and it is considered more common than role conflict among employees in organization and most people cannot distinguish role conflict from role ambiguity. In addition, they remarked that due to the lace of distinct between role ambiguity and role conflict stressors they face difficulties on how to deal with it. Thus, the uniqueness of the study would undoubtedly add more knowledge to the field. It would also raise the awareness of workload problems that academic staff face in research universities.

\section{CONTEXT AND LITERATURE REVIEW}

\section{Malaysian Universities Performance}

Malaysia has a dualistic higher education system which consists of public and private institutions (Fernandez, 2010). To encourage the public universities to compete among each other in improving their institutions' performance, initiative has been taken to classify the public universities into three groups which are research universities, comprehensive universities and focus universities. Meanwhile, research universities (RU) are on the leading edge of innovation, scholarship and solution that contribute to the developed countries' economy, security and well-being. The concept of Research University dates back to the $19^{\text {th }}$ century and since then they have been adopted by developed countries as a hub for teaching, research and innovation excellence (Atkinson \& Blanpied, 2008). Furthermore, Malaysia as a successful developing country has taken big steps to boost the achievement of the local public universities by introducing the status of research universities, and therefore five public universities have successfully been titled as research universities (Ministry of Higher Education Malaysia, 2010). Moreover, academic staff in Malaysian research universities may face more issues in their profession as the administrations are facing competitive pressure from different schools (Ahsan et al., 2009). In addition, successful educational programs rely on the significant commitments of effort on research and involvement of teaching programs, above all on the general instructor (academic staff) professionalization. Teaching staff academic, research productivities, work performance, responsibilities, and maintenance are critical to viable schools (educational establishments) (Noordin \& Jusoff, 2009). In fact, the increasing development of academic staff in research universities and building up the number of schools has been detectable in an educational organization (Mehrad et al., 2015). This development is seen as a catalyst to trigger healthy competitive nature within the public universities and it is hoped that this development will increase quality and quantity of countries invention and innovation. Because research universities have been considered as a tool to achieve countries' prosperities through knowledge based on economy, the fact that most of the countries expertise are gathered within the university atmosphere is also another factor contributed to the establishment of research universities by many developed and developing countries. Therefore, the pressures of performing research is on the shoulder of the academics who have been burdened with massive teaching workload, multi task dimensions, lack of roles clarities and also, at the same time they have to provide their time for research activities. (Ramli et al., 2013). 


\section{Organizational Stressors}

According to World Health Organization, "Health is a state of complete physical, mental and social well-being and not merely the absence of disease or infirmity" (WHO, 2010). Therefore, this study followed UK Health \& Safety Executive, (2007) that categorized organizational stress predictors contained five factors of stress including role stressors, work stressors, personal development stressors, interpersonal relationship stressors, and organizational climate stressors. Although, from those five factors this research examined the adverse impact of two predictors' of role stressors (i.e. role ambiguity and role conflict) and selected one of the predictor of work stressors (i.e. workload). The employees in organization is often found to struggle with job characteristics that cause a structural lack of fit between demands and their individual's capability to cope with such demands. From the above stressors, a number of features within the workplace have the potential of producing negative organisational outcomes which often impair mental health and physical well-being. First, those factors that are unique to the content of the work stressors and role stressors affect staff at the workplace. Other factors that impact on the performance of the staff at the workplace are personal development, interpersonal relationship, and finally organizational climate. (Michie, 2002).

\section{Role Stressors}

Role stressors or role stresses are anything about an organizational role that creates negative consequences for employees (Abbas et al., 2012). Based on previous studies, role ambiguity occurs when there is a lack of clarities in the role of a person in the organization or when the person does not know what to do or how to perform his or her role. Role conflict can also occur when employees are confronted with expectations for different roles, such as when two roles should be performed simultaneously or when performing one role prevents performing the other one. Because role clarity may serve as reinforcement to the self-efficacy belief that leads to higher performance and less stress, academics who do not have clarity about the role in workplace may experience considerable uncertainty about their role performance (Locke \& Teichler, 2007). Subsequently, higher ambiguity may also arise due to lack of clarity regarding how to juggle different academic activities of teaching, research and professional services that are necessary for the successful accomplishment of academic role. In addition, Idris (2009) found the negative impact of role conflict and role ambiguity among academics regarding their performance in public universities in Malaysia.

\section{Work Stressors}

Factors such as workload, excessive work pace (time pressures), lack of job meaningfulness, low work autonomy, external disturbances (such as noise and overcrowding) and toxic work systems are examples that can pose health damage and disrupt well-being of employees engaged in such poor working conditions. There are many work factors that cause work stressors. However, the most popular one is workload and in a broader sense, faculty workload includes performing activities like teaching, research and administrative services. According to Tight (2010) that has also mentioned by reviewing of existing literature, it is shown that in the last few decades, the issue of academic staff workload has received a lot of research attention and it is now considered as a serious concern for higher education institutions around the world. 


\section{Job Performance and Organizational Stressors among Academic Staff}

While, universities are the only institutions focus on dual core functions of knowledge creation and knowledge transmission through the processes of research, teaching and community engagement, on the other hand, research university academics do complex works in an increasingly demanding environment in both teaching and research arena. The work life of university academic staff members is predominantly framed and shaped by commitments to and performance in these functions (Atkinson \& Blanpied, 2008).

As publication records are a large part of academic staff's job performance, it would seem reasonable that high levels of organizational stressors may reduce publication efforts. In accordance to Moeller (2009) increased organizational stressors not only have considerable consequences for faculty staff research and teaching performance, but may also affect their students and the university as a whole. It is also important as the excellent performance of universities will be measured by the quantity and quality of research produced other than the quality teaching and learning. The requirement in consistency writing journal and produce research publication somehow contributes to the workload of academic staff, especially those universities which hold the status of Accelerated Programme for Excellence (APEX) and Malaysian RUs because the main criteria for an establishment of a research university are publications with impact factor journals followed by external research funding. Consequently, the triad core of the academic work which involved teaching, learning, and research has caused complexity as it demands a deeper understanding of the nature of student learning, pressures to the relocation of the teaching and research environment around learning outcomes, and due to demand of certain course that require a professional approach in university teaching (Ahmad, 2012). To sum up, the stress is more heightened in research universities as they need to maintain the status and produce article that must be published in high impact journals then publication process has an extra pressures on academics performance.

\section{METHOD}

\section{Research Design}

This study is a cross-sectional type of investigation in which the data collected at snapshot of one time because a cross sectional study is particularly suitable for estimating the prevalence of a behaviour in a population (Maree, 2010). In this research, a survey design contains a quantitative research approach employed using structured questionnaire as the main source of the research instrument (Perri \& Bellamy, 2012).

\section{Population and Sampling Technique}

The population for the current research involves academic staff who work in Malaysian research universities. Thus, there are 20 public universities spread from north to south of Malaysia, and a full-scale university is categorized as either a teaching only university or a teaching and research university. There are five public teaching and research universities in Malaysia. The institutionalization of these teaching and research universities is important for the advancement of knowledge. While other universities focus on producing graduates, these teaching and research universities place a greater 
emphasis on research and development. This study chose to examine teaching and research universities because of the presence of two job performance components: teaching and research. Hence, productivity is generally measured in these components, and their presence is important for the effectiveness of these universities' research strengthens the teaching programmes. In addition, the current study did not include public universities because it was believed that the sources of organizational stress for public universities may be significantly different due to factors such as accountability to different mission and vision, sources of funding, profit orientation and performance dimensions (Triantafillou, 2004). Moreover, this study selected research universities from the three parts of Malaysia for data collection. Therefore, using cluster sampling method for this research is to identify data collection location by divided universities geographical dispersion. Furthermore, as Ochoa (2017) revealed, using cluster sampling has advantages in researches because it is effective in primary data collection from geographically dispersed population and the need for division by location. Besides, among 209 participants, $(58.3 \%)$ of them were senior lecturers, followed by $(18.8 \%)$ associated professors and $(11.9 \%)$ participants who were lectures, while only $(11.4 \%)$ were professors.

\section{Instruments}

The first part of the structured questionnaire used to addresses the organizational stress predictors that consisted of three sub-dimensions. First sub-dimension contained the six items on role ambiguity scale was developed by Rizzo et al. (1970) which is used to measure the impression of the participants on role ambiguity. However, the responses of the participants on the role ambiguity scales reversed the score because the scale is positively worded through role clarity and recode the scales to the role ambiguities. The second sub-dimensions of the questionnaire consisted of the eight items about role conflict scale which is used to measure the participant's sense of role conflict was developed by Rizzo et al. (1970). Last, the third part of sub-dimension included the workload scales to measure academics' quantitative workload that developed by Spector and Jex (1998) and consists of five items. The second part of the questionnaire is related to job performance and divided into the two sub-dimensions including teaching activities and research productivities was developed by Moeller (2009), to assess participants' self-appraised performance in the domains of eight items on teaching activities and four items of research productivities in universities.

Validity and reliability of the current research questionnaire were assessed through pretest and post-test, regarding to sensitivity of the nature organizational stress predictors. According to Sekaran and Bougie (2010), it lessens the problems that arise from ambiguous wordings and biases, therefore, pre-test for this research is carried out by the debriefing method of personal interviews using convenience sampling for their feedback and implemented academic staff perceptions' on the 1) clarity of the words, sentences and meanings, 2) layout and sequencing of the questionnaire, and 3) the appropriateness of the questions that measures the variables presented. Based on International Institute for Educational Planning/UNESCO, Siniscalco and Auriat (2015), studies on quantitative research methods in educational planning indicated that respondents can 
introduce bias where there is a tendency for the respondent to tick systematically either the first or last category, to select what may be considered as the most socially desirable response alternative, or to answer all items in a list in the same way. A pilot study was conducted to check the reliability of the scale measurements that was measured for the internal consistency of the constructs. As the result of CMB through Harman's single factor test suggested by Podsakoff et al. (2003) to assess the presence of common method bias in single source collection data. The first factor captured only $26.18 \%$ of the total variance which is far below 50 percent, further, the total variance explained by the 9 factors was $74.96 \%$ and is well above the prescribed specification of 50 percent. Hence it can be suggested that there is no evidence of common method bias in this research.

\section{Data Analysis}

In order to examine whether organizational stress predictors' (stressors) including (role ambiguity, role conflict and workload) adversely impact on academics' job performance in research universities it was first tested whether the data showed a normal distribution. This study was employed Smart PLS to measure the hypotheses and implemented guidelines suggested by Hair et al. (2013) to report the findings. Although PLS is a nonparametric approach, which does not require the data to be normally distributed, it is still important to make sure that the data is near to normal distribution (Hassan et al., 2014). To assess non-normality, skewness and kurtosis values were obtained (Hair et al., 2013). Therefore, the results indicated that the skewness and kurtosis of the most items ranged between -1 and +1 which suggested that non-normality of data is not an issue in this research. According to Hair et al. (2011) variance based PLS software was applied when application and prediction, the phenomenon under research is relatively new or changing similar to the current model predictors (organizational stressors) and criterion (teaching and research performance).

\section{Measurement Model}

The first phase of PLS includes the evaluating of goodness of measurement model through convergent and discriminant validity (construct validity). In the present research framework there were three exogenous variables; role ambiguity, role conflict and workload stressors and job performance was endogenous variable. Therefore, before conducting hypothesis testing, it is crucial to scrutinize the measurement model to ensure the model is fit. Hence, as Figure 1 shown below while checking loadings, only one item of role ambiguity (item: role ambiguity 4), two items of workload (items: workload 2 and 3) and totally twenty eight items remained since their main indicators value were more than 0.5 which is suggested by Hair et al. (2010) that in order to make a model fit, $25 \%$ of indicators can be deleted. Moreover, the only approximate model fit criterion implemented for PLS path modelling at the present, is the standardized root mean square residual (SRMR). According to Henseler et al. (2016) SRMR as a goodness of fit measure for PLS-SEM. The SRMR is the difference between the observed correlation and the predicted correlation. While, value less than 0.10 (in conservative sense) is considered a good fit (Hair et al., 2014), and the PLS bootstrapping procedure provides the SRMR criterion. Therefore, value of 0 for SRMR 
would indicate a perfect fit. Thus, a cut-off value of 0.08 appears to be satisfactory for PLS path models as suggested by Hu and Bentler (1999). In this study, the results show that SRMR value is 0.069 which is less than cut-off value of 0.08 . Hence, the result exhibits that there was a good fit for the model with SRMR value of 0.069 for the current research models given in Figure 1 below.

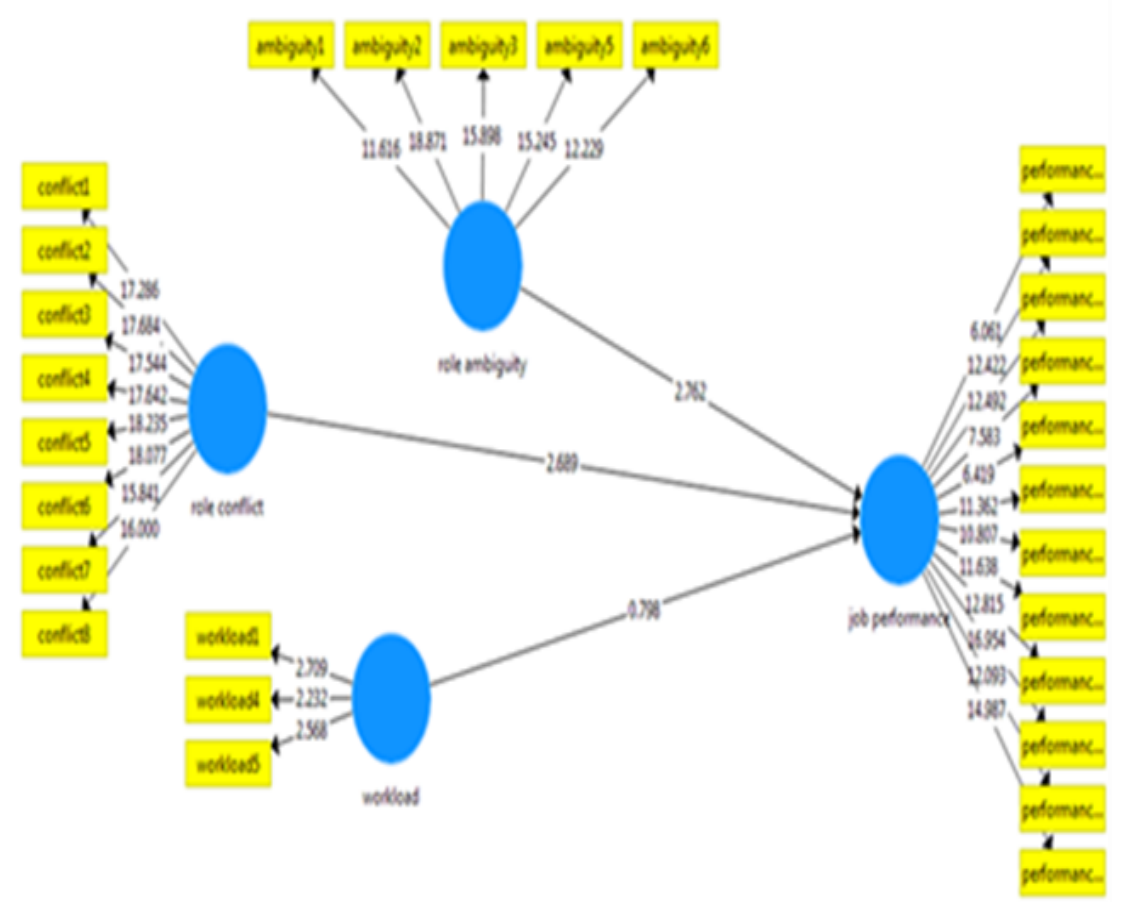

Figure 1

Full model of exogenous variables, endogenous variable

Also, because the current model contained reflective scale measurement, then convergent validity was assessed by examining the indicator loading, average variance explained (AVE) and composite reliability (CR). According to Ashill et al. (2005), when AVE is greater than 0.50 , the variance shared with a construct and its measures is greater than error. The results show that the AVE for each latent variable was above 0.50. However, AVE is ranged from 0.694 (role ambiguity) and 0.817 (role conflict), 0.731 (workload) and finally 0.532 was for (job performance). Table 1 shows that CR for each variable is more than 0.70 based on the Hair et al. (2011) suggestions which indicates that the variables used are fully reliable. The minimum value for CR was 0.890 (workload) and maximum was 0.919 (role ambiguity). While, CR values of (role conflict) was 0.944 and (job performance) was 0.941 . 
Table 1

Results of Measurement Model

\begin{tabular}{lcc}
\hline Constructs & AVE & CR \\
\hline Role Ambiguity & 0.694 & 0.944 \\
\hline Role Conflict & 0.817 & 0.919 \\
\hline Workload & 0.731 & 0.890 \\
\hline Job Performance & 0.532 & 0.941 \\
\hline
\end{tabular}

After convergent validity, the discriminant validity for reflective scale measurement is tested through the Fornell-Larcker criterion and the examination of cross-loadings are the dominant approaches for evaluating discriminant validity (as proposed by Fornell and Larcker (1981). Further, Henseler et al. (2015) demonstrates that the heterotraitmonotrait ratio of correlations (HTMT) is based on the multitrait-multi method matrix to assess discriminant validity.

Table 2

Fornell-Larcker Criterion

\begin{tabular}{lclll}
\hline & Job performance & Role ambiguity & Role conflict & Workload \\
\hline Job performance & $\mathbf{0 . 7 6 5}$ & & & \\
\hline Role ambiguity & -0.263 & $\mathbf{0 . 8 3 3}$ & & \\
\hline Role conflict & -0.272 & 0.315 & $\mathbf{0 . 9 0 4}$ & \\
\hline Workload & 0.040 & 0.067 & 0.056 & $\mathbf{0 . 8 5 5}$ \\
\hline
\end{tabular}

The results of (Table 2) shown the squared root of AVE for each construct is evidently higher than the correlation for each construct indicating adequate discriminant validity for constructs proposed in this research. Also, based on Kline (2011), if the HTMT value is below 0.85 , the discriminant validity has been established between two reflective constructs. Thereby current study reports from HTMT criterion result indicated that discriminant validity has been established between constructs, and violates of HTMT has not been found between constructs measures given in Table 3. Overall, the measurement model demonstrated adequate convergent validity and discriminant validity for this study.

Table 3

Heterotrait-Monotrait Ratio (HTMT)

\begin{tabular}{|c|c|c|c|c|}
\hline & Job performance & Role ambiguity & Role conflict & Workload \\
\hline \multicolumn{5}{|l|}{ Job performance } \\
\hline Role ambiguity & 0.268 & & & \\
\hline Role conflict & 0.280 & 0.357 & & \\
\hline Workload & 0.050 & 0.084 & 0.064 & \\
\hline
\end{tabular}

FINDINGS

\section{Structural Model}

This research was assessed the path relationship (structural model) through four steps including collinearity issues, the level of $\mathrm{R}^{2}$, standard beta, $\mathrm{t}$-values of 5000 resample via bootstrapping, and the predictive relevance $\mathrm{Q}^{2}$ in accordance to Hair et al. (2014). Collinearity issue arise when there is high correlation refers to a pair of predictors (Hair et al., 2009). This study estimated to encounter multi-collinearity issues because three 
predictors of organizational stressors measure the same attribute of an object therefore, the results of VIF values was very important. Likewise, Hair et al (2010) suggested VIF or variance inflation factor should be lower than 3. As Table 4 illustrates, results of collinearity test assessed among the independent variables in the current model and did not find any cause for using the criteria of variance inflation factor.

Table 4

Collinearity Statistics of Structural Model (Inner VIFs)

\begin{tabular}{ll}
\hline & VIF \\
\hline role ambiguity & 1.146 \\
\hline role conflict & 1.247 \\
\hline Workload & 1.018 \\
\hline
\end{tabular}

The coefficient of determination ( $\mathrm{R}^{2}$ value) depicts the structural model's predictive accuracy and is calculated as the squared correlation between a specific endogenous construct's actual and predicted values (Hair et al., 2014). According to the guideline by Cohen, (1988), the fitted multiple regression model depends on $\mathrm{R}^{2}$ and if $\mathrm{R}^{2}$ value lies between $0.02-0.12$, the model is weak, $0.13-0.25$ is moderate, and 0.26 and above is good. However, Hair et al. (2011) suggested that the judgment of $\mathrm{R}^{2}$ value is high/low depends on the specific research context. The results of the current research show that $\mathrm{R}^{2}$ value for endogenous variable (job performance) is 0.172 suggesting that $17.2 \%$ of the variance in job performance can be explained by the exogenous variables (i.e. organizational stressors). The path coefficients of the structural model have been measured and bootstrap analysis was performed to assess the statistical significance of the path coefficients. Therefore, after 5000 resample bootstrapping, this study indicated the significance of the direct relationships between role ambiguity and job performance; role conflict and job performance; workload and job performance. First, an examination of the beta and t value indicates in the Table 4 that hypothesis 1 is negatively significant. Thus, the relationship between role ambiguity and job performance found to be significant negatively based on hypotheses $\mathrm{p}<0.01 \quad(\beta=0 .-198$, t-value $=2.738)$. Second, according to the relationship between role conflict and job performance as hypothesis 2 proposed, it was found it is negatively significant based on hypotheses $p<0.01$ ( $\beta=0$. 217 , $t$-value $=2.610$ ) where based on hypothesis two, it was revealed there is a negative relationship between role conflict and job performance. Nevertheless, the third hypothesis did not show any significance. As for the hypothesis three, workload did not negatively influence on job performance and it should be noted that it is not supported as $(\beta=0.067 \mathrm{t}=805)$ that are given in Table 5 .

Table 5

The Results of Structural Model

\begin{tabular}{|c|c|c|c|c|c|}
\hline Hypothesis & Direct Relationship & Beta & SE & t-value & Decision \\
\hline H1 & RA->JB & -0.198 & 0.072 & $2.738 * *$ & Supported \\
\hline $\mathrm{H} 2$ & RC->JB & -0.217 & 0.083 & $2.610 * *$ & Supported \\
\hline $\mathrm{H} 3$ & WL->JB & 0.067 & 0.082 & 0.805 & Not Supported \\
\hline
\end{tabular}

${ }^{*} \mathrm{p}<0.05 ; * * \mathrm{p}<0.01 ; \mathrm{RA}=$ role ambiguity, $\mathrm{RC}=$ role conflict, $\mathrm{WL}=$ workload; $\mathrm{t}$ value $<1.96$

Additionally, this research assessed the predictive relevance of the model through the blindfolding procedure shown in Table 6. According to Henseler et al. (2009), this 
measure is used to assess the research model's capability to predict. $\mathrm{Q}^{2}$ value larger than zero indicates that the exogenous constructs have predictive relevance for endogenous construct (Hair et al., 2011). The result showed that all exogenous constructs in this research have predictive relevance and $\mathrm{Q}^{2}$ values were larger than zero.

Table 6

The Results of the $\mathrm{Q}^{2}$ Values

\begin{tabular}{lllll}
\hline Predictor & Endogenous & $\mathrm{R}^{2}$ & $\mathrm{Q}^{2}$ & Predictive Relevance \\
\hline Role Ambiguity & Job Performance & 0.172 & 0.511 & Yes \\
\hline Role Conflict & Job Performance & 0.172 & 0.716 & Yes \\
\hline Workload & Job Performance & 0.172 & 0.431 & Yes \\
\hline
\end{tabular}

\section{DISCUSSION}

The focus of the current study is to examine the influence of organizational stressors including role ambiguity, role conflict and workload on job performance among academic staff in research universities in Malaysia.

First of all, role ambiguity predicted has a negative significant influence on the job performance among academic staff. That indicates ambiguous academic staff deal with poor academic job performance in research universities. This finding extends the previous literature on significantly and negatively relationships between role ambiguity and job performance (June \& Mahmood, 2011). In the present study, the results show that academics were affected more by role ambiguity than other predictors in Malaysian research universities This finding is consistent with Ling (2014), who argues that one of the possible reasons of this similarity among academic staff is that they are less tolerant of role ambiguity due to the nature of academics performance in Malaysia. Therefore, frequent changes in government policies and regulations related to things such as research grants, curriculum design and key performance indicators may have contributed to a sense of ambiguity among academics in public universities. Similarly, the dynamic changes in promotional criteria may also have contributed to role ambiguity. Moreover, academics might have realized that teaching loads for the past year have left little time for them to do research (Murphy, 2014). Furthermore, it was illustrated from the findings that lack of enough clarity of academic staff role results in decline of job performance. The findings of the study also confirmed the pervious findings which were carried out higher ambiguity may arise due to lack of clarity regarding how to perform different academic activities of teaching and research that are necessary for the successful accomplishment of academic role (Catano, et al., 2007; Dua, 1994; Gillespie, et al., 2001; Idris, 2009). Next, role conflict is found to have a negative significant influence on job performance among academic staff. This means that role conflict in research universities has an adverse impact on academic performance in Malaysia. Therefore, when academic staff received the higher level of confliction in role, their job performance decreased. Thus, administrators in research universities need to decrease the pressure to perform multidisciplinary task in snap shot time. The present study finding develops the former researches' investigation on significantly and negatively relationships between role conflict and job performance (Basarudin et al., 2016; Rum et al., 2013). Finally, this study does not provide support that workload has a negative relationship on job performance among academic staff in research universities. This 
means that there is no difference between the lower level and higher level of job performance when the workload is high in their tasks. It should be noted that, in the present study, workload experienced among academic staff is characterized by the task load and deadlines, and subsequent factors including time pressures and task demand time arrangement regarding academic performance. While academic performance is related to teaching activities and research productivities among academic staff in research universities. The present results have parallel in findings by Eisenberger et al. (2005) illustrated whether academics perceived high or low workload but do not impact on the job performance, it seems that the negative influence on workload depends on workplace and definition of the roles which shows that organizational culture has important factors on how staff faced their time pressure towards the performance.

\section{CONCLUSION}

To summarize, the results confirmed that role ambiguity and role conflict are both important associations' of organizational stressors among academic staff from research universities in the present study, but academics were not affected adversely by role workload in their workplace. The question may arise as to why academic staff's job performance was not affected by workload compared to role ambiguity and role conflict in research universities. Furthermore, the present results illustrated from the findings that lack of enough clarity that leads to role ambiguities of academic staff results in decline of job performance. Therefore, it brings new contributions to the administrators of research universities. They should take into their consideration that the very explicit communication about academic staff expectation in workplace as well as establish very clear job description towards the roles. The findings of the study also confirmed the pervious research which were carried out higher ambiguity may arise due to lack of clarity regarding how to perform different academic activities of teaching and research that are necessary for the successful accomplishment of academic role (June \& Mahmood, 2011; Murphy, 2014).

On the other side role conflict negatively influenced academic staff job performance in research universities. Ultimately, it shows that conflictions among academics reached extremely due to critical thinking and high level of decision making in workplace. In addition, based on previous studies, no confusion of role expectations for academic staff happened because their schedules, time and division of tasks were arranged quite effectively (Basarudin et al., 2016; Meurs et al., 2010; Rum et al., 2013). The findings seem to reveal that among organizational factors of stress that flows in Malaysian research universities, workload was less important and academics did not care about their time pressures and deadlines as challenging stressors. This indicates that past researches revealed that the reason may be that these academics have accepted the fact that workload is part of their job and also accepted the fact that they conducted time preference between expectations and demands (workload) which is a common factor of academic role in the context of Malaysian research universities. Consequently, academic staff are very professional with standard measures of career path because they have the ability to handle high workload and recognize how to pass successfully through deadlines (Papin-Ramcharan \& Dawe, 2006). The broader ramifications of the present results are evident when considering the past studies, and it can be concluded that 
though academic staff have burdened with number of credit hours which sometimes become excessive regarding deadlines in both teaching and research activities, but it proves their capability in handling the task that how they master in teaching and research activities.

Subsequently, the results support the conceptual distinction between, role ambiguities, role conflict as role stressors also workload that did not find to be related as work stressors and provide additional evidence that they are empirically distinguishable. It is important to separate these organizational stressors because the differences in kinds of job demand theoretically distinct constructs induced different outcomes. Accordingly, university administrators would be well advised to address the root of organizational stressors by reviewing the requirements and responsibilities they bestow upon their academic staff. This study of academic stress in Malaysian universities has provided evidence that such actions are beneficial. Last but not least, the present study has provided new insights about organizational stressors in Malaysian research universities by systematically exploring the stress process among their academic staff. Henceforward, administrators of research universities can take various trough their human resource and management practices to incorporate. First, implement to reduce organizational factors of stress that adversely impact job performance, as well as embedded other kinds of support in order to increase job performance of academic staff. Overall, there are many directions that future research could take based on this study. Specifically, this research investigated three stress factors (role ambiguity, role conflict and workload) in universities. It is important to address that there still many other factors of organizational stress such as personal and impersonal stressors that should be addressed for future research. Contextually, recommendations for future research include further study that involve all public universities and private universities as well. Conceivably, academic staff at the private universities have different needs and expectations than their colleagues in the public universities. Accordingly, it would be precious to distinguish if the nature of organizational factors of stress is similar or different when a wider array of settings is remarked. Additionally, in accordance to Bakker et al., (2011) investigations suggested that different types of support may differently impact the moderating effects of social support. Thus, future research endeavours should investigate whether certain types of perceived workplace social support differ in buffering the adverse effects of occupational stressors. In particular, an increased understanding of the social support types may help focus organizational stressors interventions.

\section{REFERENCES}

Abbas, S. G. Roger, A., \& Asadullah, M. A. (2012). Impact of organizational role stressors on faculty stress \& burnout (An exploratory analysis of a public sector university of Pakistan). 4ème Colloquies International (ISEOR AOM).

Ahsan, N., Abdullah, Z., Gun Fie, Y. D., \& Alam, S. (2009). A study of job stress on job satisfaction among University Staff in Malaysia: Empirical study. European Journal of Social Science, 8(1), 121-13. 
Ashill, N. J., Carruthers, J., \& Krisjanous, J. (2005). "Antecedents and outcomes of service recovery performance in a public health care environment." Journal of Services Marketing 19(5), 293-308.

Atkinson, R. C. \& Blanpied, W. A. (2008). Research Universities: Core of the US science and technology system. Technology in Society, 30(1), 30-48.

Bakker, A. B., Hakanen, J. J., Schaufeli, W. B., Luukkonen, R., Punsksllio, A., Lusa, S., \& Schaufeli, W. B. (2011). Performance. European Journal of Work and Organizational Psychology, 20(2), 83-104. https:/doi.org/10.1002/hrm.84.

Basarudin, N. A., Yeon, A. L., Yaacob, N., \& Rahman, R. A. (2016). Faculty workload and employment benefitsin Public Universities. International Review of Management and Marketing, 6(7), 73-82.

Baron, A. R., \& Greenberg, J. (2003). Organizational Behaviour in Organization. Understanding and managing the human side of work. Canada: Prentice Hall.

Calantone, R. J. (2014). Common Beliefs and Reality About PLS: Comments on Rönkkö and Henseler, J., Dijkstra, T. K., Sarstedt, M., Ringle, C. M., Diamantopoulos, A., Straub, D. W.

Cohen, J. (1988), Statistical power analysis for the behavioral sciencies, Routledge, Hillsdale, NJ: Erlbaum.

Dua, J. K. (1994). Job stressors and their effects on physical health, emotional health and job satisfaction in a University. Journal of Educational Administration, 32, 58-78.

Eisenberger, R., Jones, J. R., Stinglhamber, F., Shanock, L., \& Randal, A. (2005). Flow experiences at work: For high need achievers alone? Journal of Organizational Behavior, 26, 755-775.

Fernandez, J. L. (2010). An exploratory study of factors influencing the decision of students to study at Universiti Sains Malaysia. 28(2), 107-136.

Fornell, C., \& Larcker, D.F. (1981). Evaluating structural equation models with unobservable variables and measurement error. Journal of Marketing Research 18, 39-50.

Gillespie, N. A., Walsh, M., Stough, C., Winefield, A. H., \& Dua, J. (2001). Occupational stress in universities: Staff perceptions of the causes, consequences and moderators of stress. Work and Stress, 15(1), 53-72.

Hair, J. F., Black, W. C., Babin, B. J., \& Anderson, R. E. (2010). Multivariate data analysis ( $7^{\text {th }}$ ed.). Englewood Cliffs: Prentice Hall.

Hair, J. F., Hult, G. T. M., Ringle, C., \& Sarstedt, M. (2014). A primer on partial least squares structural equation: modeling (PLS-SEM): Sage Publications.

Hair, J. F., Ringle, C. M., \& Sarstedt, M. (2013). Partial least squares structural equation modeling: Rigorous Applications, Better Results and Higher Acceptance. Long Range Planning, 46(1-2), 1-12. https://doi.org/10.1016/j.lrp.2013.01.001

Hair, J.F., Ringle, C. M. \& Sarstedt, M. (2011). PLS-SEM: Indeed, a silver bullet. Journal of Marketing Theory and Practice 19(2), 139-151.

Hassan. S. T.; Ramayah. T. Mohamad. O. \& Moghsoudi. A. (2014). E-lifestyle, customer satisfaction, and loyalty among the generation Y mobile users. Asian Social Science 11(4), 157.

Health and Safety Executive. (2007). Managing the causes of work-related stress: A step by step approach using the Management Standards. Surrey: Crown. 
Henseler. J., Hubona. G., \& Ash Ray, P. (2016). Using PLS path modelling in new technology research: updated guidelines. Industrial Management \& Data Systems. https://doi.org/10.1108/IMDS-09-2015-0382

Henseler, J., Ringle, C. M., \& Sarstedt, M. (2015). A new criterion for assessing discriminant validity in variance-based structural equation modeling. Journal of the Academy of Marketing Science, 43(1), 115-135.

Henseler, J., Ringle, C. M., \& Sinkovics, R. R. (2009). The use of partial least squares path modeling in international marketing. Advances in International Marketing 20, 277-320.

Hu, L. T., \& Bentler, P.M. (1999). Cut off criteria for fit indexes in covariance structure analysis: Conventional criteria versus new alternatives. Structural Equation Modeling, 6, 1-55.

Jacob, W. J., Xiong, W., \& Ye, H. (2015). Professional development programmes at worldclass universities. Palgrave Communications, 1, 15002.

Jex, S. M. \& Bliese, P. D. (1999). Efficacy beliefs as a moderator of the impact of workrelated stressors: A multilevel study. Journal of Applied Psychology, 84, 349-361.

Jonker, L. C. (2016). Stress in a College Workplace and its Relationship with Certain Correlations and Predictive Variables. Stellenbosch University.

June, S., \& Mahmood, R. (2011). The relationship between role ambiguity, competency and person-job fit with the job performance of employees in the service sector SMEs in Malaysia. Business Management Dynamics, 1(2), 79-98.

Kaur, A., Noman, M., \& Awang-Hashim, R. (2018). The role of goal orientations in students' perceptions of classroom assessment in higher education. Assessment \& Evaluation in Higher Education, 43(3), 461-472.

Kinman, G., \& Jones, F. (2008). Effort-reward imbalance, over-commitment and work-life conflict: Testing an expanded model. Journal of Managerial Psychology, 23(3), 236-251.

Kline, R. B. (2011) Principles and Practice of Structural Equation Modeling. Guilford Press, New York.

Li, L. (2012). Role Ambiguity among School Principals in China and Finland. Retrieved from https://jyx.jyu.fi/bitstream/handle/123456789/41912/URN:NBN:fi:jyu201307302100.pdf? sequence $=1$

Ling, S. M. (2014). An Investigation on Factors of Work Stress Influence Job Performance : Moderating By Social Support, (May), 115.

Locke, W., \& Teichler, U. (2007). Introduction, the changing conditions for academic work and career in select countries. Werkstattberichte, 6, 7-14.

Maree, J. G. (2010). The career interest profile ( $2^{\text {nd }}$ ed.). Randburg, South Africa: Jopie van Rooyen and Partners.

Mehrad, A.; Redzuan, H. H. M. R. B. \& Abdullah, H. (2015). The Role of personality factors on job satisfaction among academic staff at public research university. Journal of Educational, Health and Community Psychology, 4(1), 20-28.

Meurs, J. A., Gallagher, V. C., \& Perrewé, P. L. (2010). The role of political skill in the stressor-outcome relationship: Differential predictions for self-and other- reports of political skill. Journal of Vocational Behavior, 76(3), 520-533. 
Michie, S. (2002). Causes and management of stress at work. Journal of Occupational and Environmental Medicine, 59, 1, 67-72.

Ministry of Higher Education Malaysia (MOHE) (2010). The National Higher Education Action Plan: Kementerian Pendidikan Malaysia. Retrieved from www.moe.gov.my

Moeller, Ch. (2009). Stressors, strains and social support: Occupational experiences of university professors. http://scholar.uwindsor.ca/etd

Murphy, J. (2014). Managing professional development of academic staff to enhance university performance. Thesis (Doctor of Business Administration (DBA). University of Bath.

Noordin, F., \& Jusoff, K. (2009). Levels of job satisfaction amongst Malaysian academic staff. Asian social science, 5(5), 122-126.

Ochoa, C. (2017). Random sampling cluster sampling. Netquest. Retrieved from https://www.netquest.com/blog/en/cluster-sampling.

Papin-Ramcharan, J. I., \& Dawe, R. A. (2006). Open access publishing: a developing country view. http://www.firstmonday.org/issues/issue11_6/ papin/index.html

Perri, P., \& Bellamy, C. (2012). Principles of Methodology: Research Design in Social Science. London: SAGE Publications Ltd.

Ram, P. (2013). Relationship between job satisfaction and job performance in the public sector-A Case Study from India. International Journal of Academic Research in Economics and Management Sciences, 2(2), 16-35.

Ramli, N., Zainol, Z. A., Aziz, J. A., Ali, H. M., Hassim, J., Hussein, W. M. H. W. ..., \& Yaakob, N. I. (2013). The concept of research university: The implementation in the context of Malaysian university system. Asian Social Science, 9(5), 307-317.

Rizzo, J. R., House, R. J., \& Lirtzman, S. I. (1970). Role conflict and ambiguity in complex organizations. Administrative Science Quarterly, 15, 150-163.

Rum J., Troena E. A., Hadiwidjoyo D., \& Surachman (2013). Role of conflict toward employee performance (Studies in Government Budgeting Team at Kendari). Int $J$ Bus Manage Invent 2(11), 39-51.

Sekaran, U., \& Bougie, R. (2010) Research methods for business: A Skill Building Approach ( $5^{\text {th }}$ ed.). Chichester, West Sussex, UK: John Wiley \& Sons Ltd.

Siniscalco, M. T., \& Auriat, N. (2005). Questionnaire design: Quantitative research methods in educational planning. Paris: UNESCO International Institute for Educational Planning.

Spector, P. E., \& Jex, S. M. (1998). Development of four self-report measures of job stressors and strain: Interpersonal conflict at work scale, organizational constraints scale, quantitative workload inventory, and physical symptoms inventory. Journal of Occupational Health Psychology, 3(4), 356-367.

Tight, M. (2010). Are Academic Workloads Increasing? The Post-War Survey Evidence in the UK. Higher Education Quarterly, 64(2), 200-215.

Triantafillou, P. (2004). From blood to public office: Constituting bureaucratic rulers in colonial Malaya. Journal of Southeast Asian Studies, 35, 21-40.

World Health Organization. (2010). Healthy workplaces: A model for action for employers, workers, policymakers and practitioners. Geneva: WHO. 